\title{
Desigualdades, pandemia COVID-19 e possíveis impactos sobre o risco de suicídio no Brasil
}

\author{
Tiago C. Zortea ${ }^{1,2}$
}

(iD) https://orcid.org/0000-0002-8451-0555

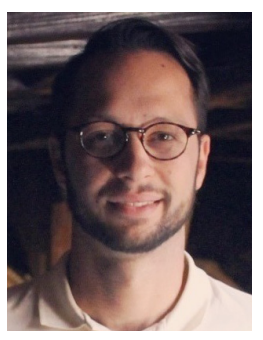

Os países subdesenvolvidos e em desenvolvimento são os mais afetados pelo suicídio no mundo, representando $79 \%$ dessas mortes ${ }^{(1)}$. Incluído neste quadro está o Brasil. Embora as causas sejam multifatoriais e complexas, diversos estudos apontam que as taxas de suicídio estão fortemente associadas às experiências de pobreza, baixo poder socioeconômico, desemprego, e outras desigualdades(2). A existência de tais associações estabelece um cenário crítico diante do avanço da pandemia COVID-19. Portanto, não apenas para a saúde física, o impacto da pandemia sobre a saúde mental em dimensões populacionais pode ser profundo. Enquanto medidas de distanciamento físico e quarentena reduzem a propagação do vírus, os efeitos adversos de tais medidas sobre o risco de suicídio aumentam de modo superior nos contextos em que as desigualdades são mais acentuadas. Em outras palavras, os fatores de risco anteriormente existentes podem se intensificar na presença das mudanças provocadas pela pandemia. Alguns exemplos são brevemente expostos aqui.

\section{Impacto econômico}

Estudos de simulação econômica preveem altas chances de uma recessão mundial resultante de diversos fatores, incluindo fechamento de estabelecimentos - e consequente aumento do desemprego -, queda do consumo e do investimento. Considerando que estressores de ordem econômica contribuem para o aumento do risco de suicídio, têm-se sugerido que a provisão governamental (e.g., transferências de renda, auxílio financeiro aos que tiveram contrato profissional suspenso ou jornada de serviço e salário reduzidos, auxílio desemprego, etc.) podem contribuir para a redução dos riscos de suicídio(3).

\footnotetext{
${ }^{1}$ University of Glasgow, Institute of Health and Wellbeing, Suicidal Behaviour Research Laboratory, Escócia.

2 Co-Chair, Early Career Group - Associação Internacional de Prevenção ao Suicídio.
}

\section{Como citar este artigo}

Zortea TC. Inequalities, COVID-19 pandemic, and possible impacts on suicide risk in Brazil. SMAD, Rev Eletrônica Saúde Mental Álcool Drog. 2020;16(4):1-2. doi: https://dx.doi.org/10.11606/issn.1806-6976.smad.2020.0142. 


\section{Distanciamento físico e solidão}

Medidas de quarentena são historicamente reconhecidas como eficazes na redução da propagação de doenças. Concomitantemente, as evidências enfatizam proximidade emocional e percepção de pertencimento como vitais na prevenção de suicídios. Uma particularidade do contexto em que a COVID-19 ocorre quando comparada às pandemias anteriores é a possiblidade de manter contato social remotamente. Enquanto este é um aspecto altamente positivo na prevenção, o risco se acentua à luz das desigualdades: a restrição de acesso ao telefone ou à internet, seja por limitação financeira ou de qualquer outra ordem pode reduzir a proximidade emocional, aumentando as percepções de solidão, abandono e, por sua vez, o risco de suicídio. Junto a esses fatores encontra-se a suspensão temporária de cerimônias religiosas. É sabido que a religião pode operar (para heterossexuais) como fator de proteção contra o suicídio, dados seus elementos que promovem pertencimento, sentido e suporte social. Esses fatores também se aplicam a outros grupos sociais (de caráter não religioso) que propiciam tais elementos comunitários, cujo acesso impedido pode agravar o risco. Apesar de este ser um desafio, torna-se necessário o desenvolvimento de alternativas que supram a proximidade emocional, respeitando as medidas de quarentena impostas pela pandemia.

\section{Acesso aos serviços de saúde mental}

O distanciamento físico também institui desafios para os serviços de saúde mental em, no mínimo, duas frentes: a provisão de acesso alternativo remoto e o aumento das demandas de saúde mental como efeito da pandemia. 0 primeiro está relacionado à inclusão digital - e.g. muitos pacientes não possuem acesso a telefones ou à internet, não sabem operar aparelhos eletrônicos, ou portam algum tipo de deficiência que os impossibilita de usar tais tecnologias. O segundo desafio decorre do aumento da demanda por serviços de saúde mental, uma vez que a população tende a vivenciar episódios mais frequentes de ansiedade e depressão devido a uma série de fatores resultantes da pandemia (e.g. medo de contração do vírus, solidão, aumento da violência doméstica, etc.). Outrossim, é notório o aumento do número de pessoas enlutadas devido à morte de entes próximos causadas pela COVID-19. A experiência do luto torna-se ainda mais difícil com a restrição de funerais e a ausência de outros entes próximos devido à imposição do distanciamento físico. A combinação dessas experiências à restrição dos serviços de saúde mental, na ausência de fatores de proteção, pode elevar o risco de suicídio.

Apesar de esta não ser uma experiência exclusiva do Brasil, os desencadeamentos da pandemia no país são únicos e demandam de intervenções preventivas equivalentes às realidades locais. Num país onde 31,1 milhões de seus cidadãos não possuem acesso a saneamento básico e 11,6 milhões vivem em adensamento excessivo(4), as desigualdades aumentam não apenas os riscos de morte por COVID-19, mas também por suicídio. Essas mortes, no entanto, não são inevitáveis. A prevenção do suicídio deve ser implementada através de diferentes vias metodológicas e níveis de intervenção. Uma das vias mais importantes e urgentes em escala populacional é redução das desigualdades que produzem vulnerabilidade estrutural e aumento do risco.

\section{Referências}

1. World Health Organization. Suicide [Internet]. World Health Organization Newsroom. 2019 [cited 2019 Oct 23 ]. Available from: https://www.who.int/news-room/fact-sheets/detail/suicide

2. Iemmi V, Bantjes J, Coast E, Channer K, Leone T, McDaid D, et al. Suicide and poverty in low-income and middleincome countries: a systematic review. Lancet Psychiatry. 2016;3(8):774-83. doi: 10.1016/S2215-0366(16)30066-9 3. Gunnell D, Appleby L, Arensman E, Hawton K, John A, Kapur N, et al. Suicide risk and prevention during the COVID-19 pandemic. Lancet Psychiatry. 2020. doi: https://doi.org/10.1016/ S2215-0366(20)30171-1

4. Silveira D. Coronavírus e desafios à prevenção: Brasil tem 31,3 milhões sem água encanada e 11,6 milhões em casas "superlotadas." G1 Economia [Internet]. 2020 Mar 23;[cited 2020 Mar 18]. Available from: https://g1.globo. com/economia/noticia/2020/03/28/coronavirus-e-desafios-a-prevencao-brasil-tem-313-milhoes-sem-aguaencanada-e-116-milhoes-em-casas-superlotadas.ghtml 